\title{
PENENTUAN JUMLAH MESIN DAN OPERATOR LINTASAN PRODUKSI UTAMA BERDASARKAN TARGET PRODUKSI BARU DI CV. SINAR ALBASIA UTAMA
}

\author{
Fran Setiawan $^{1)}$, Yosef Daryanto ${ }^{2)}$ dan Yosephine Suharyanti ${ }^{2)}$ \\ ${ }^{1)}$ Program Studi Teknik Industri, Universitas Katolik Parahyangan, Bandung \\ ${ }^{2)}$ Program Studi Teknik Industri, Universitas Atma Jaya Yogyakarta, Yogyakarta \\ e-mail: fransetiawan@unpar.ac.id
}

\begin{abstract}
ABSTRAK
CV Sinar Albasia Utama (SAU) merupakan sebuah perusahaan manufaktur kayu yang memproduksi barecore. CV SAU memiliki 2 lintasan produksi utama dan 1 lintasan produksi re-size Target produksi saat ini sebanyak 475 lembar barecore per lintasan utama per shift. Seiring berjalannya waktu, CV SAU mengalami peningkatan permintaan sehingga pemilik CV SAU ingin menaikkan target produksi lintasan utama menjadi 532 lembar barecore per lintasan per shift. Penelitian ini bertujuan untuk menentukan jumlah mesin dan operator lintasan produksi utama berdasarkan target produksi yang baru pada CV SAU. Penelitian ini dimulai dengan terlebih dahulu mempelajari proses produksi barecore, menghitung waktu baku masing-masing proses produksi, menghitung waktu baku masing-masing proses produksi untuk satu lembar barecore, dan menghitung jumlah mesin dan operator pada lintasan produksi utama sesuai target produksi yang baru. Rencana target produksi yang baru membutuhkan tambahan 1 buah mesin cross cut, 2 operator cross cut, 1 operator proses sortir 2A operasi 2, 1 operator proses sortir 2B, 1 operator pada proses conveyor loyang, 1 kelompok yang terdiri dari 3 operator pada proses dempul, 1 operator pada proses radial arm saw, dan 1 orang operator pada proses pengeleman.
\end{abstract}

Kata kunci: barecore, lintasan produksi, jumlah mesin, jumlah operator

\begin{abstract}
CV Sinar Albasia Utama (SAU) is a manufacture company which produced barecore. CV SAU has two main production lines and one re-size production line. Currently, the production target at CV SAU is 475 sheets of barecore. As time goes by, the demand of CV SAU increase and the owner wants to set the new production target to 532 sheets of barecore. The purpose of this research is to determine the number of machines and operators of CV SAU's main production line based on new production target. This research is started with understanding production process of barecore, calculating standard time of each production process of barecore, calculating standard time of each production process of barecore to produce one sheet of barecore dan calculating the number of machines and operator needed by new production target. The new production target is need an addition of 1 cross cut machine, 2 operators in cross cut process, 1 operator in second operation of $2 A$ sorting process, 1 operator in $2 B$ sorting process, 1 operator in conyeyor loyang process, 1 group consist of 3 operators at radial arm saw process amd 1 operator at gluing process.
\end{abstract}

Keywords: barecore, production line, number of machines, number of operators

\section{PENDAHULUAN}

CV Sinar Albasia Utama merupakan sebuah perusahaan manufaktur yang memproduksi barecore. Barecore merupakan produk olahan kayu berupa lembaran yang terdiri susunan kayu-kayu kecil yang disebut dengan corepiece. Barecore digunakan sebagai hiasan pada dinding, sebagai alas lantai rumah sebelum diberi keramik atau dapat diolah kembali menjadi produk kayu lainnya seperti meja, kursi, tempat tidur, dll. Produk barecore yang diproduksi dipasarkan baik ke dalam maupun ke luar negeri. Produk barecore yang dihasilkan terdiri dari barecore grade A dan barecore grade $\mathrm{B}$ yang dibedakan menurut kualitas barecore yang dihasilkan.

CV Sinar Albasia Utama berproduksi secara flowshop dengan fasilitas produksi disusun sesuai dengan urutan pengerjaan produk sehingga membentuk suatu lintasan produksi. Saat ini CV Sinar Albasia Utama memiliki dua buah lintasan produksi utama dan satu buah lintasan produksi re-size. Lintasan produksi utama digunakan untuk memproduksi barecore mulai dari balken yang dipotong hingga menjadi barecore sedangkan lintasan produksi re-size digunakan untuk memproduksi 
barecore dari hasil corepiece yang tidak lolos seleksi pada lintasan utama.

Seiring berjalannya waktu, CV Sinar Albasia Utama mengalami peningkatan permintaan sehingga target produksi yang ada saat ini yaitu 475 lembar barecore per lintasan utama per shift dipandang tidak lagi cukup untuk mengakomodasi permintaan sehingga pihak manajemen CV Sinar Albasia Utama ingin menaikkan target produksi lintasan utama menjadi 532 lembar barecore per lintasan per shift.

Oleh karena itu diperlukan adanya perhitungan untuk menentukan jumlah mesin dan lintasan produksi utama pada CV Sinar Albasia Utama untuk mengakomodasi target produksi yang baru.

Penelitian mengenai perhitungan jumlah mesin yang dibutuhkan sudah pernah dilakukan oleh beberapa penelitian terdahulu. San dkk. melakukan penelitian pada sebuah perusahaan manufaktur yang memproduksi koper [1]. Permasalahan yang terjadi adalah tidak terpenuhinya target produksi yang disebabkan oleh kurangnya jumlah mesin yang digunakan serta tata letak pabrik yang tidak efisien. Penelitian ini dimulai dengan mempelajari proses produksi, perhitungan waktu standar, perhitungan waktu mesin dan melakukan analisa tata letak pabrik agar menjadi lebih efisien.

Gozali dkk. menghitung jumlah mesin yang dibutuhkan untuk mengusulkan rancangan tata letak produksi pada perusahaan yang memproduksi konveyor untuk industri pertambangan batu bara [2]. Penentuan jumlah mesin dilakukan dengan terlebih dahulu menghitung waktu baku untuk masing-masing proses produksi konveyor, dilanjutkan dengan membuat multi product process chart karena banyaknya komponen pada konveyor dan menghitung kebutuhan mesin teoritis.

Nurhasanah dan Bima melakukan perbaikan rancangan tata letak lantai produksi pada industri yang memproduksi lemari pakaian dan menggunakan MPPC untuk menyusun dan mengetahui jumlah mesin yang dibutuhkan untuk setiap departemen [3].

Putri dkk. menghitung kebutuhan mesin untuk merancang tata letak produksi pada industri pembuat mesin pertanian [4]. Perhitungan kebutuhan mesin produksi dimulai dengan menghitung waktu proses per proses produksi mesin pertanian, target produksi, availability, efisiensi mesin dan reliabilitas mesin.

Menurut Tompkins dkk., jumlah dari peralatan atau mesin yang diperlukan untuk sebuah operasi atau proses produksi disebut sebagai fraksi peralatan [5]. Fraksi peralatan dapat ditentukan dengan membagi total waktu yang diperlukan untuk melakukan operasi dengan jumlah waktu operasi yang tersedia. Total waktu yang diperlukan untuk melakukan operasi dari suatu produk adalah waktu baku dari operasi dan jumlah berapa kali suatu operasi dikerjakan.

Menurut Stephens dan Meyers, waktu baku adalah waktu yang diperlukan untuk memproduksi produk pada sebuah stasiun kerja yang dikerjakan oleh pekerja yang berkualifikasi baik, bekerja dalam keadaan normal dan melakukan pekerjaan tertentu [6]. Menurut Sutalaksana dkk., dalam pengukuran waktu hal-hal mengenai kewajaran kerja, kenormalan bekerja serta kelonggaran pekerja juga harus diperhatikan yaitu dengan menambahkan nilai penyesuaian serta kelonggaran [7]. Faktor penyesuaian dibutuhkan untuk mendapatkan waktu penyelesaian yang wajar oleh operator dari suatu pekerjaan sedangkan faktor kelonggaran ditambahkan untuk mengakomodasi tiga hal yaitu kelonggaran untuk kebutuhan pribadi, menghilangkan rasa lelah dan untuk hambatanhambatan yang tidak dapat dihindarkan seperti menerima petunjuk dari pengawas.

Pada penelitian ini, perhitungan jumlah mesin dan operator yang dibutuhkan untuk mengakomodasi target produksi yang baru dilakukan dengan membagi total waktu yang diperlukan untuk melakukan operasi dengan jumlah waktu operasi yang tersedia.

\section{METODOLOGI PENELITIAN}

Penelitian ini dilakukan dengan terlebih dahulu menghitung waktu proses masingmasing proses produksi barecore, menghitung waktu baku masing-masing proses produksi barecore dengan menambahkan faktor 
penyesuaian serta kelonggaran, menghitung waktu baku masing-masing proses berdasarkan satu lembar barecore dan menghitung jumlah kebutuhan mesin dan pekerja yang dibutuhkan oleh lintasan utama. Data yang diperlukan dalam penelitian ini adalah data produk dan bahan baku, jumlah mesin pada lintasan utama saat ini, proses produksi barecore, waktu siklus tiap proses produksi, dan data turun ukur barecore.

\section{HASIL DAN PEMBAHASAN \\ Data Produk dan Bahan Baku}

Bahan baku berupa kayu balken albasia dengan ukuran panjang $100 \mathrm{~cm}$ dan $130 \mathrm{~cm}$; ukuran lebar $8 \mathrm{~cm}, 10 \mathrm{~cm}, 12 \mathrm{~cm}, 14 \mathrm{~cm}$ dan 16 $\mathrm{cm}$; ukuran tebal $5 \mathrm{~cm}$. Bahan baku terdiri dari balken grade $\mathrm{A}$, balken grade $\mathrm{B}$ dan balken afkir yang dipisahkan menurut kualitas balken yang datang.

Produk yang dihasilkan berupa barecore kualitas grade A dan barecore kuaitas grade $\mathrm{B}$ dengan ukuran panjang $2440 \mathrm{~mm}$, lebar 1220 $\mathrm{mm}$ dan tebal $13 \mathrm{~mm}$. Barecore yang telah jadi di packaging menggunakan plastik packaging. Satu hasil packaging barecore disebut sebagai satu pallet barecore yang terdiri dari 82 lembar barecore untuk pallet besar dan 24 lembar barecore untuk pallet kecil.

\section{Proses Produksi Barecore}

Data proses produksi barecore adalah sebagai berikut

a. Balken yang sudah didinginkan kemudian dimasukkan ke dalam lantai produksi. Balken kemudian dipotong menjadi 3 bagian di mesin jumping cross cut.

b. Balken yang telah terpotong oleh mesin jumping cross cut kemudian dikerjakan di mesin double planeruntuk diratakan bagian atas dan bawahnya. Pisau potong pada mesin ini sudah diset pada angka tertentu (standar ketebalan). Perhitungan ini dipengaruhi oleh lebar standar yang sudah ditentukan untuk produk barecore dan juga tergantung dari tebal bahan baku kayu (balken) yang dikirim oleh supplier.

c. Balken yang keluar dari proses double planer akan diseleksi apakah hasil perataan balken dari mesin double planer baik atau tidak. Jika hasil perataan baik maka balken akan langsung dikerjakan di mesin gangrip. Jika hasil perataan tidak baik balken tersebut nantinya akan dikerjakan lagi di mesin double planer sehingga ukurannya menjadi lebih kecil (proses turun ukur). Proses turun ukur balken adalah ukuran 46 mm, $44 \mathrm{~mm}, 43 \mathrm{~mm}, 41 \mathrm{~mm}, 39 \mathrm{~mm}$, dan $36 \mathrm{~mm}$.

d. Balken masuk ke mesin gangrip untuk dipotong menjadi strip yang disebut corepiece.

e. Corepiece yang keluar dari mesin gangrip kemudian masuk ke proses sortir. Proses sortir dibedakan menjadi proses sortir A dan B. Proses sortir A terdiri atas 3 proses. Pada proses sortir A pertama corepiece hasil keluaran gangrip dibuang kedua tepi kanan dan kirinya. Proses sortir A kedua melakukan proses seleksi dari hasil sortir A pertama. Corepiece yang lolos seleksi dari sortir A kedua dibawa ke sortir A ketiga untuk disortir lebih lanjut. Pada proses sortir A ketiga akan dipilih corepiece yang sempurna untuk masuk ke proses shapper dan corepiece yang termasuk grade $\mathrm{A}$ masuk ke proses conveyor loyang. Corepiece yang tidak lolos seleksi pada proses sortir A akan diseleksi kembali pada proses sortir B. Pada proses sortir B akan dipilih corepiece grade $\mathrm{B}$ yang masuk ke proses conveyor loyang, corepiece yang akan diproses di cross cut (corepiece yang sebagian baik sehingga dapat diambil bagian yang baik) dan corepiece yang akan masuk proses re-size (corepiece yang sebagian besar buruk).

f. Corepiece yang masuk proses cross cut akan dipotong bagian yang jelek. Bagian yang jelek dari corepiece tersebut ada yang akan masuk proses re-size dan ada yang akan dianggap sebagai skrap yang nantinya akan digunakan sebagai bahan bakar boiler.

g. Corepiece hasil seleksi proses sortir dan hasil seleksi cross cut yang tergolong ke dalam grade $\mathrm{A}$ dan grade $\mathrm{B}$ kemudian masuk ke proses penataan secara vertikal di conveyor loyang.

h. Bila hasil tatanan di conveyor loyang sudah penuh maka tatanan corepiece tersebut akan 
didorong ke proses radial arm saw untuk dipotong sesuai dengan ukuran panjang barecore yang dihasilkan.

i. Corepiece hasil seleksi proses sortir A ketiga yang sempurna kemudian dibawa ke proses shapper.

j. Hasil dari proses shapper kemudian dibawa ke proses finger joint press untuk digabung membentuk sisi tepi barecore.

k. Hasil dari proses finger joint press dan radial arm saw kemudian diberi lem pada bagian atasnya.

1. Susunan corepiece yang telah diberi lem pada bagian atasnya kemudian disusun secara horisontal sehingga membentuk barecore.

m. Barecore masuk ke dalam mesin press dengan tujuan untuk merekatkan corepiececorepiece yang telah diberi lem.

n. Barecore diberi dempul setelah dikeluarkan dari mesin press. Tujuan pendempulan ini adalah agar tidak terdapat rongga udara dalam barecore. Rongga udara dalam barecore dapat mengakibatkan lepasnya lem.

o. Barecore masuk ke proses packaging.

Jumlah Mesin pada Lintasan Utama Saat ini

Data jumlah mesin pada lintasan utama produksi barecore di CV Sinar Albasia Utama dapat dilihat pada Tabel 1.

Tabel 1. Data Jumlah Mesin pada Lintasan Utama Saat Ini

\begin{tabular}{cll}
\hline No & \multicolumn{1}{c}{ Nama Proses } & $\begin{array}{c}\text { Jumlah Mesin dan } \\
\text { Operator }\end{array}$ \\
\hline 1 & Jumping Cross Cut & 2 mesin dan 4 operator \\
2 & Conveyor Jumping & 1 mesin dan 2 operator \\
3 & Double Planer & 1 mesin dan 1 operator \\
4 & Meja Sortir 1 & 1 meja dan 2 operator \\
5 & Gangrip & 1 mesin dan 3 operator \\
6 & Meja Sortir 2 & 1 meja dan 6 operator \\
7 & Conveyor Loyang & 1 mesin dan 2 operator \\
8 & Radial Arm Saw & 1 mesin dan 2 operator \\
9 & Meja Lem & 1 meja dan 1 operator \\
10 & Arranging Press & 1 kelompok (4 operator) \\
11 & Press Utama & 1 mesin \\
12 & Dempul & 1 kelompok (3 operator) \\
11 & Shapper & 1 mesin dan 1 operator \\
12 & Finger Joint Press & 1 mesin dan 1 operator \\
13 & Cross Cut & 2 mesin dan 4 operator \\
\hline
\end{tabular}

\section{Data Waktu Siklus}

Data waktu siklus tiap proses produksi barecore didapat dengan melakukan pengukuran langsung pada lantai produksi CV Sinar Albasia Utama dengan menggunakan jam henti. Pengukuran dilakukan sebanyak 35 kali untuk tiap proses kemudian dilakukan uji keseragaman data dan uji kecukupan data sebelum dilakukan perhitungan waktu baku tiap proses produksi barecore.

\section{Data Turun Ukur Barecore}

Data turun ukur barecore digunakan untuk mengetahui berapa lembar barecore yang mengalami proses turun ukur pada ukuran tertentu sehingga diketahui beban kerja proses double planer dan sortir 1. Turun ukur dilakukan jika hasil perataan balken pada proses double planer tidak lolos pada proses sortir 1 sehingga balken akan di proses lagi pada double planer dengan ukuran yang lebih kecil. Data turun ukur barecore diambil dari catatan operator conveyor loyang. Data turun ukur barecore (dalam satuan lembar) selama 2 bulan dapat dilihat pada Tabel 2 .

Tabel 2. Data Turun Ukur Barecore

\begin{tabular}{|c|c|c|c|c|c|c|}
\hline \multicolumn{6}{|c|}{ Ukuran } & \multirow[b]{2}{*}{ Total } \\
\hline $\begin{array}{c}46 \\
(\mathrm{~mm})\end{array}$ & $\begin{array}{c}44 \\
(\mathrm{~mm})\end{array}$ & $\begin{array}{c}43 \\
(\mathrm{~mm})\end{array}$ & $\begin{array}{c}41 \\
(\mathrm{~mm})\end{array}$ & $\begin{array}{c}39 \\
(\mathbf{m m})\end{array}$ & $\begin{array}{c}36 \\
(\mathrm{~mm})\end{array}$ & \\
\hline 7087 & 2822 & 823 & 394 & 116 & 129 & 11371 \\
\hline
\end{tabular}

\section{Perhitungan Waktu Baku tiap Proses Produksi Barecore}

Perhitungan waktu baku digunakan untuk mengetahui waktu baku penyelesaian masingmasing proses produksi barecore setelah menambahkan faktor penyesuaian dan faktor kelonggaran pada waktu siklus. Waktu baku nantinya digunakan untuk menghitung jumlah mesin dan operator yang diperlukan dalam satu lintasan produksi utama. Perhitungan waktu baku tiap proses produksi barecore dapat dilihat pada Tabel 3.

\section{Perhitungan Waktu Baku Berdasarkan Satu Lembar Barecore}

Waktu baku yang telah ditentukan belum didasarkan pada waktu baku untuk menghasilkan satu lembar barecore sehingga 
Tabel 3. Perhitungan Waktu Baku Tiap Proses Produksi Barecore

\begin{tabular}{clcccc}
\hline No & \multicolumn{1}{c}{ Proses } & $\begin{array}{c}\text { Faktor } \\
\text { Penyesuaian }\end{array}$ & $\begin{array}{c}\text { Waktu Normal } \\
\text { (detik) }\end{array}$ & $\begin{array}{c}\text { Faktor } \\
\text { Kelonggaran }\end{array}$ & $\begin{array}{c}\text { Waktu Baku } \\
\text { (detik) }\end{array}$ \\
\hline 1 & Jumping cross cut & 0,02 & 5,25 & 0,17 & 6,14 \\
2 & Double planer & 0,02 & 1,38 & 0,11 & 1,53 \\
3 & Sortir 1 & 0,05 & 1,40 & 0,16 & 1,62 \\
4 & Gangrip & 0,03 & 1,28 & 0,11 & 1,42 \\
5 & Sortir 2A operasi 1 & 0,01 & 0,209 & 0,13 & 0,236 \\
6 & Sortir 2A operasi 2 & 0,01 & 0,367 & 0,13 & 0,415 \\
7 & Sortir 2A operasi 3 & 0,01 & 0,380 & 0,13 & 0,429 \\
8 & Sortir 2B & 0,01 & 2,099 & 0,13 & 2,372 \\
9 & Conveyor loyang & 0,05 & 49,24 & 0,11 & 54,66 \\
10 & Radial Arm Saw & 0,05 & 45,42 & 0,11 & 50,42 \\
11 & Pengeleman & 0,06 & 47,28 & 0,12 & 52,95 \\
12 & Arranging press & 0,05 & 42,03 & 0,11 & 46,64 \\
13 & Press & - & 900 & - & 900 \\
14 & Dempul & 0,00 & 85,71 & 0,11 & 95,14 \\
15 & Shapper & 0,05 & 31,98 & 0,11 & 34,82 \\
16 & Finger joint press & 0,05 & 15,90 & 0,11 & 17,65 \\
17 & Cross cut & 0,02 & 0,883 & 3,258 \\
18 & Arranging single planer & 0,05 & 0,90 & 0,11 & 0,99 \\
19 & Single planer & 0,02 & 8,13 & 0,11 & 9,02 \\
\hline
\end{tabular}

perlu adanya perhitungan waktu baku proses berdasarkan satu lembar barecore. Hal ini dikarenakan target produksi CV Sinar Albasia Utama dalam lembar barecore. Waktu baku ini yang nantinya akan digunakan untuk menentukan jumlah mesin dan operator pada lintasan utama.

Menurut manager produksi CV Sinar Albasia Utama, satu lembar barecore memerlukan sebelas batang balken sehingga waktu baku proses jumping cross cut untuk satu lembar barecore adalah waktu baku yang digunakan untuk memotong sebelas batang barecore. Waktu baku proses jumping cross cut menjadi 11 x 6,14 detik =67,54 detik.

Proses jumping cross cut memotong balken menjadi 3 batang yang lebih kecil sehingga terdapat 33 buah potongan balken yang akan masuk ke proses double planer yang berasal dari proses jumping cross cut. Proses double planer juga memproses potongan balken yang tidak lolos seleksi pada proses sortir 1 untuk dikerjakan ulang sehingga ukuran tebalnya menjadi lebih kecil yang disebut proses turun ukur. Proses turun ukur balken di mesin double planer adalah ukuran $46 \mathrm{~mm}, 44$ mm, $43 \mathrm{~mm}, 41 \mathrm{~mm}, 39 \mathrm{~mm}$, dan $36 \mathrm{~mm}$.

Dari data jumlah turun ukur barecore dapat dihitung jumlah yang harus diproses pada tiap pengerjaan turun ukur dengan memisalkan jumlah total turun ukur barecore sebagai $n$, jumlah ukuran $46 \mathrm{~mm}$ sebagai $n_{1}$, jumlah ukuran $44 \mathrm{~mm}$ sebagai $n_{2}$, jumlah ukuran 43 mm sebagai $n_{3}$, jumlah ukuran $41 \mathrm{~mm}$ sebagai $n_{4}$, jumlah ukuran $39 \mathrm{~mm}$ sebagai $n_{5}$, jumlah ukuran $36 \mathrm{~mm}$ sebagai $n_{6}$ dan memisalkan jumlah yang harus diproses pada ukuran $46 \mathrm{~mm}$ sebagai $N_{1}$, jumlah yang harus diproses pada ukuran $44 \mathrm{~mm}$ sebagai $N_{2}$, jumlah yang harus diproses pada ukuran $43 \mathrm{~mm}$ sebagai $N_{3}$, jumlah yang harus diproses pada ukuran $41 \mathrm{~mm}$ sebagai $N_{4}$, jumlah yang harus diproses pada ukuran $39 \mathrm{~mm}$ sebagai $N_{5}$, jumlah yang harus diproses pada ukuran $44 \mathrm{~mm}$ sebagai $N_{6}$. Jumlah yang harus diproses pada tiap pengerjaan turun ukur adalah sebagai berikut:

Ukuran $46 \mathrm{~mm}=n=11371$ lembar $=N_{1}$

Ukuran $44 \mathrm{~mm}=N_{1}-n_{1}=4284$ lembar $=N_{2}$

Ukuran $43 \mathrm{~mm}=N_{2}-n_{2}=1462$ lembar $=N_{3}$

Ukuran $41 \mathrm{~mm}=N_{3}-n_{3}=639$ lembar $=N_{4}$

Ukuran $39 \mathrm{~mm}=N_{4}-n_{4}=245$ lembar $=N_{5}$

Ukuran $36 \mathrm{~mm}=N_{5}-n_{5}=129$ lembar $=N_{6}$

Dengan mencari proporsi untuk jumlah yang harus diproses pada tiap pengerjaan turun ukur, dapat dicari beban kerja untuk proses double planer dengan cara mengalikan proporsi jumlah yang harus diproses pada tiap pengerjaan turun ukur dengan jumlah total hasil 
Tabel 4. Hasil Perhitungan Beban Kerja Proses Double Planner

\begin{tabular}{cccc}
\hline Ukuran & $\begin{array}{c}\text { Jumlah yang harus } \\
\text { dikerjakan }\end{array}$ & Proporsi & $\begin{array}{c}\text { Jumlah yang harus dikerjakan } \\
\text { pada satu lembar barecore }\end{array}$ \\
\hline $46 \mathrm{~mm}$ & 11371 & 1,000 & 33 \\
$44 \mathrm{~mm}$ & 4284 & 0,377 & $12,433 \approx 13$ \\
$43 \mathrm{~mm}$ & 1462 & 0,129 & $4,243 \approx 5$ \\
$41 \mathrm{~mm}$ & 639 & 0,056 & $1,854 \approx 2$ \\
$39 \mathrm{~mm}$ & 245 & 0,022 & $0,711 \approx 1$ \\
$36 \mathrm{~mm}$ & 129 & 0,011 & $0,374 \approx 1$ \\
\hline & & Total & 55 \\
\cline { 2 - 3 }
\end{tabular}

dari jumping cross cut yaitu sebanyak 33 potongan balken. Proporsi untuk jumlah yang harus diproses pada tiap pengerjaan turun ukur dapat dicari dengan membagi jumlah yang harus diproses pada ukuran tertentu dibagi dengan jumlah total turun ukur, sebagai contoh proporsi untuk ukuran $44 \mathrm{~mm}$ adalah 4284 / $11371=0,377$. Proporsi untuk ukuran 46 mm adalah 1 karena semua balken yang masuk proses double planer mengalami proses turun ukur dari bahan baku setebal $50 \mathrm{~mm}$ menjadi $46 \mathrm{~mm}$.

Setelah didapatkan jumlah yang harus diproses pada tiap pengerjaan berdasarkan 33 potongan balken didapat hasil bahwa untuk membuat satu lembar barecore, proses doubleplaner harus memproses 55 potongan balken. Waktu baku proses double planner menjadi 55 x 1,53 detik = 84,15 detik. Hasil perhitungan dapat dilihat pada Tabel 4 .

Proses sortir 1 mengecek hasil dari proses double planer. Bila hasil double planer baik maka potongan balken dibawa ke proses gangrip dan bila hasil double planer tidak baik akan dikerjakan ulang di proses double planer (proses turun ukur) dan kemudian akan dicek lagi pada proses sortir 1 sehingga beban kerja proses sortir 1 sama dengan beban kerja proses double planner yaitu harus mensortir sebanyak 55 potongan balken untuk membuat satu lembar barecore. Waktu baku proses sortir 1 menjadi 55 x 1,62 detik = 89,1 detik.

Proses gangrip membutuhkan sebanyak 33 potongan balken dari proses sortir 1 untuk membuat satu lembar barecore berdasarkan hasil potongan dari jumping cross cut sehingga waktu baku proses gangrip 1 menjadi 33 x 1,42 detik $=46,86$ detik.

Proses gangrip memotong potongan balken menjadi corepiece. Satu potongan balken dipotong menjadi 6 buah corepiece sehingga output proses gangrip sebanyak 33 x 6 $=198$ buah corepiece untuk membuat satu lembar barecore.

Untuk melakukan pengamatan pada proses sortir, dilakukan pengambilan video proses sortir untuk mengetahui proporsi corepiece yang tidak lolos seleksi. Pada proses sortir 2A operasi 1 didapatkan proporsi corepiece yang lolos seleksi sebesar 0,666 dan yang tidak lolos seleksi 0,334. Proporsi pada proses sortir 2A operasi 2 adalah corepiece yang lolos seleksi sebesar 0,907 dan yang tidak lolos seleksi sebesar 0,093. Proporsi pada proses sortir 2A operasi 3 adalah corepiece yang lolos seleksi sebesar 0,914, corepiece yang sempurna sebesar 0,068 dan yang tidak lolos seleksi sebesar 0,018. Corepiece yang tidak lolos seleksi akan masuk ke proses sortir 2B. Melalui proporsi ini dapat dihitung jumlah yang harus diseleksi oleh tiap proses sortir 2 untuk membuat satu lembar barecore.

Waktu baku proses sortir 2A operasi 1 menjadi $198 \times 0,236$ detik $=46,73$ detik. Waktu baku proses sortir $2 \mathrm{~A}$ operasi 2 menjadi $132 \mathrm{x}$ 0,415 detik $=54,78$ detik. Waktu baku proses sortir $2 \mathrm{~A}$ operasi 3 menjadi $120 \times 0,429$ detik = 51,48 detik.

Proses sortir 2B mensortir corepiece yang tidak lolos seleksi pada tiap proses sortir 2A. Melalui video yang direkam, pada proses sortir 2B didapatkan proporsi corepiece grade $\mathrm{B}$ sebesar 0,155, corepiece yang masuk proses cross cut sebesar 0,555 dan corepiece yang masuk proses re-size sebesar 0,289. Melalui hasil corepiece yang tidak lolos pada tiap proses sortir 2B dapat dihitung bahwa waktu baku untuk proses sortir 2B menjadi 80 x 2,372 detik $=189,76$ detik. 
Proses sortir 2B mensortir corepiece yang masuk ke proses cross cut. Melalui proporsi pada proses sortir 2B dan hasil sortir 2B untuk membuat satu lembar barecore dapat dihitung bahwa waktu baku untuk proses cross cut menjadi 44 x 3,258 detik = 143,35 detik.

Proses shapper dalam satu kali proses mampu menampung sebanyak 24 corepiece. Corepiece hasil dari proses shapper dibawa ke proses finger joint press. Proses finger joint press membutuhkan 12 buah corepiece hasil dari proses shapper untuk membuat satu lembar barecore sehingga waktu baku proses shapper menjadi 34,82 detik / 2 = 17,41 detik.

Proses finger joint press dalam satu kali proses membutuhkan 6 buah corepiece untuk disatukan menjadi tepi barecore. Satu lembar barecore terdiri dari 2 tepi sehingga waktu baku untuk proses finger joint press menjadi $2 \mathrm{x}$ 17,65 detik $=35,3$ detik.

Waktu baku proses lainnya tidak diperlukan penyesuaian karena waktu baku proses tersebut sudah berdasarkan satu lembar barecore. Hasil perhitungan waktu baku berdasarkan satu lembar barecore dapat dilihat pada Tabel 5.

Tabel 5. Hasil Perhitungan Waktu Baku Berdasarkan Satu Lembar Barecore

\begin{tabular}{clc}
\hline No & \multicolumn{1}{c}{ Proses } & $\begin{array}{c}\text { Waktu Baku } \\
\text { (detik) }\end{array}$ \\
\hline 1 & Jumping cross cut & 67,54 \\
2 & Double planer & 84,15 \\
3 & Sortir 1 & 89,1 \\
4 & Gangrip & 46,86 \\
5 & Sortir 2A operasi 1 & 46,73 \\
6 & Sortir 2A operasi 2 & 54,78 \\
7 & Sortir 2A operasi 3 & 51,48 \\
8 & Sortir 2B & 189,76 \\
9 & Conveyor loyang & 54,66 \\
10 & Radial Arm Saw & 50,42 \\
11 & Pengeleman & 52,95 \\
12 & Arranging press & 46,64 \\
13 & Press & 900 \\
14 & Dempul & 95,14 \\
15 & Shapper & 17,41 \\
16 & Finger joint press & 35,3 \\
17 & Cross cut & 143,35 \\
\hline
\end{tabular}

\section{Perhitungan Jumlah Mesin dan Operator Lintasan Produksi Utama dengan Target Produksi yang Baru}

Perhitungan jumlah mesin dan operator lintasan produksi utama dengan target produksi 532 lembar barecore per lintasan dapat dihitung dengan menggunakan perhitungan sebagai berikut:

Jumlah mesin atau pekerja yang dibutuhkan dalam satu lintasan $=$ (Target produksi per line $\mathrm{x}$ waktu baku operasi per unit) : waktu kerja efektif per hari per shift

Waktu kerja efektif per hari per shift didapatkan dari waktu kerja tersedia per hari per shift dikurangi waktu untuk melakukan setup mesin dan perawatan mesin setiap shiftnya. Sebagai contoh perhitungan untuk jumlah mesin atau pekerja pada proses jumping cross cut dengan target produksi 532 lembar adalah sebagai berikut:

Proses jumping cross cut

Jumlah mesin atau pekerja yang dibutuhkan:

$=$ (532 unit/hari/shift x 67,54 detik/unit) : $25200 \mathrm{detik} / \mathrm{mesin} / \mathrm{hari} / \mathrm{shift}$

$$
=1,43 \approx 2 \text { mesin }
$$

Perhitungan untuk proses lainnya dapat dilihat pada Tabel 6.

Tabel 6. Hasil Perhitungan Jumlah Mesin dan Operator

\begin{tabular}{cll}
\hline No & \multicolumn{1}{c}{ Nama Proses } & $\begin{array}{c}\text { Jumlah Mesin dan } \\
\text { Operator }\end{array}$ \\
\hline 1 & Jumping Cross Cut & 2 mesin dan 4 operator \\
2 & Conveyor Jumping & 1 mesin dan 2 operator \\
3 & Double Planer & 1 mesin dan 1 operator \\
4 & Meja Sortir 1 & 1 meja dan 2 operator \\
5 & Gangrip & 1 mesin dan 3 operator \\
6 & Meja Sortir 2 & 1 meja dan 8 operator \\
7 & Conveyor Loyang & 1 mesin dan 3 operator \\
8 & Radial Arm Saw & 1 mesin dan 2 operator \\
9 & Meja Lem & 1 meja dan 2 operator \\
10 & Arranging Press & 1 kelompok (4 operator) \\
11 & Press Utama & 1 mesin \\
12 & Dempul & 2 kelompok (6 operator) \\
11 & Shapper & 1 mesin dan 1 operator \\
12 & Finger Joint Press & 1 mesin dan 1 operator \\
13 & Cross Cut & 3 mesin dan 6 operator \\
\hline
\end{tabular}

\section{KESIMPULAN}

Rencana target produksi yang baru sebanyak 532 lembar per lintasan produksi utama membutuhkan tambahan 1 buah mesin 
cross cut, 2 operator cross cut, 1 operator proses sortir 2A operasi 2, 1 operator proses sortir 2B, 1 operator pada proses conveyor loyang, 1 kelompok yang terdiri dari 3 operator pada proses dempul serta pelibatan satu operator untuk ikut bekerja pada proses radial arm saw dan pelibatan satu operator untuk ikut bekerja pada proses pengeleman.

\section{DAFTAR PUSTAKA}

[1] San, G.S., Wahjudi, D., Sugiarto, 2000, Analisa Tata Letak Pabrik untuk Meminimalisasi Material Handling pada Pabrik Koper, Jurnal Teknik Mesin, Vol 2, p. 41-49, Jurusan Teknik Mesin, Universitas Kristen Petra.

[2] Gozali, L., Ariyanti, S., Putrajaya, L., 2013, The Proposed Layout Design using Factory Systematic Layout Planning Method at PT Jaya Laksa Utama, Proceeding $6^{\text {th }}$ International Seminar on Industrial Engineering and Management, Indonesia.

[3] Nurhasanah, N., Simawang, B.P., 2013, Perbaikan Rancangan Tata Letak Lantai Produksi di CV XYZ, Jurnal AL-AZHAR INDONESIA SERI SAINS DAN TEKNOLOGI, Vol 2, No 2.
[4] Putri, N.T., Fithri, P., Taufik, M., 2015, Facility Layout Design on the Agricultural Machinery Industry, Proceedings of the International Multi Conference of Engineers and Computer Scientist, Vol II, Hongkong.

[5] Tompkins, J.A., White, John A., Bozer, Yavus A., Tanchocho, J.M.A., 2010, Facilities Planning, Fourth Edition, John Wiley \& Sons, Inc, United States of America.

[6] Stephens, M.P., Meyers, F.E., 2013, Manufacturing Fasilities Design and Material Handling, Fifth Edition, Purdue University Press, West Lafayette, Indiana.

[7] Sutalaksana, I.Z., Anggawisastra, R., Tjakraatmadja, J.H., 2006, Teknik Perancangan Sistem Kerja, Edisi 2, Penerbit ITB, Bandung. 